\title{
Immunological and Hematological Effects of Perinatal Exposure to Antiretroviral Drugs in HIV-exposed, Non-infected Children
}

\author{
IRA SHAH \\ Incharge Pediatric HIV, TB and Liver Clinic, B.J.Wadia Hospital for Children \\ Consultant in Pediatric Infectious Diseases and Pediatric Hepatology, Nanavati Hospital, Mumbai. \\ irashah@pediatriconcall.com
}

$\mathrm{N}$ on-infected children born to HIV-infected mothers are increasing worldwide due to effective prevention of parent to child transmission of HIV (PPTCT) programs. It is known that the use of highly active antiretroviral therapy (HAART) reduces viral replication, increases CD4+ T cell counts and decrease immune activation and apoptosis in HIV-infected individuals [1]. The introduction of antiretrovirals (ARVs) in HIV-infected pregnant women has drastically decreased vertical transmission of HIV. However, changes in both immunological response and hematological parameters have been detected in HIVexposed uninfected newborns and attributed to both HIV protein exposure in-utero as well as due to exposure to ARVs for a prolonged time [2]. Further, mitochondrial dysfunction in infants exposed to Nucleoside reverse transcriptase inhibitors (NRTIs) has been reported in utero which could lead to lactic acidosis $[3,4]$. Hematological changes are often reversed soon but T-cell lymphocyte changes are known to last even longer [2]. The paper by Wongnoi, et al. [5] in the current issue highlights the important aspect of hematological alterations and impaired thymic function in newborns of HIV-infected mothers on ART.

HIV-1 specific immune responses have been reported in children who have been exposed to the virus yet remained uninfected leading to a state of immune activation [6]. CD8+ immune responses to HIV-1 Env, $\mathrm{Gag}$, and Nef proteins have been shown in the peripheral blood of these infants early after birth [7]. In addition HIV-1 specific CD8+ interferon gamma responses have been detected in HIV-exposed uninfected infants between 15-50 months of age [8]. However, these studies were prior to use of maternal HAART and is likely that these children were exposed to high levels of maternal HIV viremia $[7,8]$. Even in children exposed perinatally to HAART, HIV-1 specific immune responses even in the setting of low maternal viremia leads to low level of immune activation which is highest in the cord blood and lower in the peripheral blood [6]. This may be either due to infected maternal lymphocytes or activated antigen presenting cells which may have microtransfused across the placenta stimulating the fetal immune system [6]. Another immunological phenomenon observed is an increase in B lymphocytes especially the CD19/CD5+ in cord blood of HIV exposed newborns [2] with increased $\mathrm{B}$ cell apoptosis in later life [6]. Therefore, these infants are still at an increased risk for severe infections. A case series in South Africa has reported eight HIV exposed uninfected children who had unusual or severe infections, where their mothers had received ARVs during pregnancy [9]. Lower CD4+ cell count in cord blood has been reported due to low thymic output [10]. Similarly, other markers for thymic output such as T-cell receptor excision circles (TRECs) for CD4+ cells have also been noticed to be lower in these children as stated by the study by Wongkoi, et al. in this issue [5]. Immune activation is known to recede over time; however, lower CD4+ levels and higher B-cell apoptosis has been noticed in older children 6-18 years of age who are HIV-exposed but uninfected [10].

Several ARVs, most importantly Zidovudine (AZT) and other NRTIs are known to cause anemia in adults and children. Exposure to perinatal HAART is associated with mild, reversible anemia in HIV-exposed uninfected children [11]. In developing countries, the incidence and severity of anemia may be greater due to micronutrient deficiency [12]. In children with limited exposure to AZT, the anemia is usually microcytic whereas in children with prolonged exposure to AZT ( $>6$ months), the anemia is usually macrocytic [13]. The explanation for the association of maternal use of ARV during pregnancy and neonatal hemoglobin levels is probably secondary to the reduced maturation of the erythroid progenitor line in fetuses exposed to medication [14].

In summary, HIV exposed uninfected children have long term immunological changes due to either in utero exposure to HIV proteins and also due to exposure to ARVs. Anemia due to exposure to NNRTIs, particularly 
AZT, is mild and reversible. Mitochondrial depletion can lead to mitochondrial dysfunction that needs to be evaluated further.

Competing interest: None stated; Funding: Nil.

\section{REFERENCES}

1. Gougeon ML, Lecoeur H, Sasaki Y. Apoptosis and the CD95 system in HIV disease: impact of highly active antiretroviral therapy (HAART). Immunol Lett. 1999;66:97103.

2. Borges-Almeida E, Milanez H, Vilela MMS, Abramczuk BM, Reis- Alves SC, Metze K, et al. The impact of maternal HIV infection on cord blood lymphocyte subsets and cytokine profile in exposed non-infected newborns. BMC Infect Dis. 2001;11:38.

3. Shah I. Lactic acidosis in HIV-exposed infants with perinatal exposure to antiretroviral therapy. Ann Trop Pediatr. 2009;29:257-61.

4. Blanche S, Tardieu M, Rustin P, Slama A, Barret B, Firtion $\mathrm{G}$, et al. Persistent mitochondrial dysfunction and perinatal exposure to antiretroviral nucleoside analogues. Lancet. 1999;354:1084-9.

5. Wongkoi R, Penvieng N, Singboottra P, Kingkeow D, Oberdorfer $\mathrm{P}$, Sirivatanapa $\mathrm{P}$, et al. Hematological alterations and impaired thymic function in newborns of HIV-infected mothers receiving antiretroviral drugs. Indian Pediatr. 2013;50:567-72.

6. Legrand FA, Nixon DF, Loo CP, Ono E, Chapman JM, Miyamoto M, et al. Strong HIV-1 specific T cell responses in HIV-1 exposed uninfected infants and neonates revealed after regulatory T cell removal. PLoS One. 2006;1:e102.
7. Cheybier R, Langlade- Demoyen P, Marescot MR, Blanche S, Blondin G, et al. Cytotoxic T lymphocyte responses in the peripheral blood of children both to human immunodeficiency virus-1-infected mothers. Eur J Immunol. 1992;22:2211-17.

8. De Maria A, Cirillo C, Moretta L. Occurrence of human immunodeficiency virus type 1 (HIV-1)-specific cytolytic $\mathrm{T}$ cell activity in apparently uninfected children born to HIV-1 infected mothers. J Infect Dis. 1994;170:1296-9.

9. Slogrove AL, Cotton MF, Esser MM. Severe infections in HIV-exposed uninfected infants: clinical evidence of immunodeficiency. J Trop Pediatr. 2010;56:75-81.

10. Miyamoto M, Pessoa SD, Ono E, Machado DM, Salomao $\mathrm{R}$, de M Succi RC, et al. Low CD4+ T-cell levels and B-cell apoptosis in vertically HIV-exposed noninfected children and adolescents. J Trop Pediatr. 2010; 56: 427-32.

11. Fernández Ibieta M, Ramos Amador JT, González Tomé MI, Guillén Martín S, Bellón Cano JM, Navarro Gómez M, et al. Anaemia and neutropenia in a cohort of non-infected children of HIV-positive mothers. An Pediatr (Barc). 2008;69:533-43.

12. Totin D, Ndugwa C, Mmiro F, Perry RT, Jackson JB, Semba RD. Iron deficiency anemia is highly prevalent among human immunodeficiency virus-infected and uninfected infants in Uganda. J Nutr. 2002;132:423-9.

13. Dryden-Peterson S, Shapiro RL, Hughes MD, Powis K, Ogwu A, Moffat C, et al. Increased risk of severe infant anemia after exposure to maternal HAART, Botswana. J Acquir Immune Defic Syndr. 2011;56:428-36.

14. El Beitune P, Duarte G. Antiretroviral agents during pregnancy: consequences on hematologic parameters in HIV-exposed, uninfected newborn infant. Eur J Obstet Gynecol Reprod Biol. 2006; 128: 59-63. 